\title{
Microcréditos ecuatorianos: incentivo a la reducción de la pobreza y mejora del ingreso familiar
}

\section{Ecuadorian microcredits: incentive for poverty reduction and family income improvement}

\section{*ANA CARVAJAL SALGADO, LEONELA ESPINOZA PÁRRAGA}

Universidad Estatal de Milagro, Cdla. Universitaria Km. 1.5 vía,

Km, 26, Milagro, Guayas, Ecuador

*acarvajals1@unemi.edu.ec

\section{RESUMEN}

Los microcréditos son sistemas de financiamiento que brindan las entidades bancarias para incentivar y mejorar la calidad de vida de las personas que pretenden realizar emprendimientos. Si bien no es la única opción que tiene la sociedad para reducir la pobreza, es probablemente uno de los mecanismos más utilizado para superar las limitaciones económicas. El objetivo de este trabajo es analizar las implicaciones de los microcréditos ecuatorianos en la reducción de la pobreza mediante una revisión documental y estudio de campo para determinar su impacto en la mejora del ingreso familiar. Se empleó una metodología documental, de carácter exploratorio y descriptivo, a través de una investigación de campo. Se aplicó un muestreo no probabilístico con una muestra de 68 beneficiarios del microcrédito de la ciudad de Milagro perteneciente a la provincia del Guayas. En conclusión, el microcrédito en Ecuador es un mecanismo para aliviar la pobreza, siempre que el crédito sea bien administrado, porque incrementa el ingreso y el consumo de las familias pobres. El 51 \% de los encuestados afirmó que el microcrédito incrementó sus niveles de ingresos y el 29 $\%$ manifestó que a través del crédito mejoró su calidad de vida. Es así que, el microcrédito alivia significativamente la pobreza patrimonial y alimentaria que, al ser analizada desde la perspectiva de las familias, se concluye que contribuye al aumento de su calidad de vida.

Palabras claves: Microcréditos, entidades bancarias, ingreso familiar, emprendimiento, negocios. 


\section{ABSTRACT}

Microcredits are financing systems provided by banks to encourage and improve the quality of life of people who intend to undertake projects. Although it is not the only option that society has to reduce poverty, but it is probably one of the most used to overcome financial constraints. The objective of this work is to analyze the implications of Ecuadorian microcredits in poverty reduction, through a documentary review and field study, in order to determine its impact on improving family income. An exploratory and descriptive documentary methodology was used through field research. A non-probability sampling was applied, using a sample of 68 beneficiaries of the microcredit from the city of Milagro province of Guayas. In conclusion, microcredit in Ecuador is a mechanism to alleviate poverty, if that credit is well managed, because it could increase the income and consumption of poor families. About $51 \%$ of those surveyed stated that microcredit increased their income levels and $29 \%$ stated that the credit was a pathway to improved their quality of life. Thus, microcredit significantly improves patrimonial and food poverty; which, when analyzed from the perspective of families, concludes that it contributes to the improvement of their quality of life.

Keywords: Microcredits, banks, family income, entrepreneurship, business.

\section{INTRODUCCIÓN}

nivel mundial. Es así que en la actualidad existen varias instituciones enfocadas en las microfinanzas, mismas que fueron creadas con un solo objetivo que es proporcionar microcréditos a todas las familias del mundo. Estas instituciones se benefician de ello al poder crear, mejorar, crecer e impulsar sus propios negocios mejorando su calidad de vida.

En Ecuador los microcréditos se volvieron populares a partir de 1986 cuando el país se interesó en implementar medidas para el desarrollo y crecimiento agrícola en bancos como la Previsora y el Banco Nacional de Fomento, fundándose de esta manera la Corporación Financiera Nacional (CFN) para créditos productivos. La intención era apoyar a los sectores más vulnerables, pero en 1998 debido a la mala administración y entregas sin garantías de los créditos, algunas instituciones se quedaron sin liquidez. Se entró en una crisis financiera y perdieron los bancos su credibilidad. Esta crisis empezó a estabilizarse en el 2001 con la dolarización.

El microcrédito es el préstamo de una pequeña cantidad de dinero cuyo monto está condicionado a la capacidad de pago del deficitario de recursos y su duración es en períodos cortos (Castillo, 2008). Según la Junta de Regulación Monetaria y Financiera (2015):

...el microcrédito se otorga a una persona natural o jurídica con un nivel de ventas anuales inferior o igual a USD 100000.00 , o a un grupo de prestatarios con garantía solidaria destinado a financiar actividades de producción y/o comercialización en pequeña escala, cuya fuente principal de pago la constituye el producto de las ventas o ingresos generados por dichas actividades, verificados adecuadamente por la entidad del Sistema Financiero Nacional.

El microcrédito es clave para el desarrollo económico de la sociedad, al permitir un incremento de la competitividad de las empresas, 
además permite la reducción de la pobreza y el desempleo al impulsar la creación de emprendimientos (Orozco, 2015).

Los microcréditos desde su inicio fueron creados para financiar y ayudar al desarrollo económico de las personas; por tal motivo, como idea de negocio, beneficia a todos los involucrados: la parte deudora y la acreedora. Se espera que en un futuro no muy lejano más personas puedan gozar de este privilegio e innoven sus emprendimientos, mejorando su calidad de vida conforme vayan creciendo a nivel económico y puedan educarse financieramente. Así se podrán mantener al día sobre los nuevos sucesos o cambios que contribuyan a mejorar sus negocios, siendo los microcréditos importantes para el desarrollo social (Inglada, Sastre, \& de Miguel Bilbao, 2015).

El objetivo de este artículo es analizar las implicaciones de los microcréditos ecuatorianos en la reducción de la pobreza, mediante una revisión documental y estudio de campo para determinar su impacto en la mejora del ingreso familiar.

El trabajo se divide en cuatro partes: primero, una revisión literaria, en la cual constarán las conceptualizaciones más relevantes sobre el tema; en la segunda sección se describe la metodología a aplicar para el desarrollo del trabajo; en la tercera se encuentra el análisis de los resultados y finalmente, la conclusión como cuarta sección.

\section{Desarrollo del microcrédito en el Ecuador}

Uno de los negocios estratégicos en América Latina son las instituciones microfinancieras que nacen como herramienta para combatir la pobreza a través de los servicios financieros (Montalvo Corzo, Vázquez Parra, \& Amézquita Zamora, 2018).

El servicio financiero que más impulso tiene es el microcrédito. De acuerdo con Gutiérrez Nieto (2003), el microcrédito es la parte esencial del campo de las microfinanzas que se refiere a la provisión de servicios financieros para personas de escasos recursos económicos. Al respecto, las Naciones Unidas declararon al 2005 como el año del microcrédito, con la finalidad de impulsar su desarrollo en todo el mundo. Bajo el mismo enfoque, se consideran a los micro-ahorros como el segundo servicio bancario que ha cobrado importancia en los últimos años (Aguilar Pinto, Tuñón Pablos, \& Morales Barragán, 2017).

Hoy en día, el microcrédito es un servicio prestado por las instituciones financieras, tanto en los países desarrollados como los que están en vías de desarrollo, perteneciendo el Ecuador a este último caso y donde, con el transcurrir de treinta años, esta alternativa financiera ha alcanzado su etapa de madurez, contribuyendo en mejoras a los ingresos del país y demostrando que genera un impacto positivo en el bienestar de las familias. El país busca reactivar la economía a través de pequeños empresarios o emprendedores, indagando la forma en que puedan beneficiarse ambas partes (estado y ciudadanos), sin que alguna salga perjudicada, siempre respetando y cumpliendo las respectivas leyes (Salgado \& Andrade, $2011)$. Para obtener este objetivo se planteó en el 2012 el cambio de la matriz productiva, que busca entre otras cosas, nuevos esquemas de generación, distribución y redistribución de la riqueza.

Los bancos públicos y privados del Ecuador, como parte del incentivo a la mejora del ingreso familiar, tienen por finalidad otorgar microcréditos para apoyar el desarrollo social, económico y productivo del país. Estos microcréditos están dirigidos a personas que tienen pequeños negocios con características que van desde el no contar con un lugar físico para ejercer su actividad, hasta ejercerlo de forma ambulante; y por tales circunstancias, desean mantenerlos o mejorarlos debido a que, por su naturaleza, poseen capitales limitados y cuentan generalmente con personal integrado por miembros de su familia. Salgado (2011) menciona que "este grupo es parte estructural de la economía del Ecuador y Latinoamérica, puesto que representa el 60\% de la población económicamente activa y aporta entre el $10 \%$ y $15 \%$ del producto interno bruto en el caso del Ecuador" (pp 21-22).

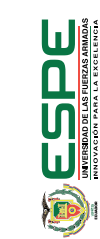


Cabe recalcar que en Ecuador existen instituciones financieras que no consideran el programa de microcréditos en su portafolio y otras que se dedican exclusivamente a esta línea, como es el caso de los bancos privados Coopnacional, D-Miro, Finca, Machala y Visión Fund Ecuador, por lo que tienen un alta acogida y tienden a especializarse en este producto financiero. Con relación a los bancos públicos, Mazón, (2018) menciona que

mediante Resolución No. 391-2017-F del 31 de julio de 2017, la Junta de Política y Regulación Monetaria y Financiera, dispone que para el año 2017, Banecuador deberá canalizar sus recursos principalmente a los segmentos de microcrédito y vivienda de interés público.

La banca ecuatoriana ofrece una variedad de microcréditos, conviene resaltar que existen cuatro tipos que tienen diferentes denominaciones según el monto a prestar a los microempresarios. A continuación, se detallan las clasificaciones de los microcréditos:

- Microcrédito minorista: El Banco Central del Ecuador (2012) menciona que los microcréditos minoristas

Son aquellas acciones de crédito cuyo monto por operación y saldo adeudado en microcréditos a la institución financiera sea menor o igual a USD 3 000, que son otorgadas a microempresarios que registran un nivel de ventas anuales inferior a USD 100000 , a trabajadores por cuenta propia, o a un grupo de prestatarios con garantía solidaria.
- Microcrédito de acumulación ampliada: El Banco Central del Ecuador (2012) menciona en su libro de codificaciones lo siguiente:

Son aquellas operaciones de crédito superiores a USD 10000 otorgadas a microempresarios y que registran un nivel de ventas anuales inferior a USD 100 000, a trabajadores por cuenta propia, o un grupo de prestatarios con garantía solidaria. Cuando el saldo adeudado en microcréditos con la Institución financiera supere los USD 10000 indiferentemente del monto, la operación pertenecerá al segmento de microcrédito de acumulación ampliada.

- Microcrédito agrícola y ganadero: Conforme la Junta de Política Monetaria y Financiera (2019), mediante Resolución 496-2019-F de 28 de febrero de 2019 se crea el segmento de microcrédito agrícola y ganadero que consiste en "operaciones otorgadas a solicitantes de crédito, cuyo saldo adeudado en microcréditos a la entidad del Sistema Financiero Nacional, sea menor o igual a USD 100 000, incluyendo el monto de la operación solicitada para financiar actividades agrícolas y ganaderas"

A pesar de que los bancos otorgan microcréditos a pequeños empresarios o emprendedores, todavía existen familias cuyos niveles de ingresos producto de alguna actividad comercial, no son lo suficientemente adecuados para mantener apropiadas condiciones de vida. Es por esto que el Banco Central del Ecuador $(B C E)$, como ente regulador e institución gubernamental que fija los costos máximos del uso del dinero, busca reglar tasas de interés que se ajusten a la economía de todos los estratos sociales. Es así que la Junta de Regulación Monetaria Financiera (2018), mediante Resolución No. 437-2018-F de 26 de enero de 2018 redujo 2 \% en las tasas de interés máximas (Tabla 1) para todos los sub-segmentos del microcrédito, de tal forma que se incentive la producción y el empleo a través del financiamiento. 
La Tabla 1 comprende los costos de microcréditos que oferta la banca ecuatoriana. Se puede observar que las entidades poseen una tasa efectiva vigente a la fecha de la operación regulada por el BCE. Los costos crediticios están afectados por las tasas de captación de recursos de las instituciones financieras. Con la reducción de las tasas de intereses se logra a) Minimizar los gastos financieros y las mensualidades a pagar, y b) Aumentar el flujo de recursos financieros hacia nuevas actividades productivas.

Tabla 1: Tasa de interés efectiva máxima para el segmento microcréditos

\begin{tabular}{|c|c|c|c|}
\hline \multirow{2}{*}{ Tipos de Microcréditos } & Diciembre 2017 & Diciembre 2018 & Diciembre 2019 \\
\hline & $\%$ anual & $\%$ anual & $\%$ anual \\
\hline Agrícola y Ganadero & $*$ & * & 20.97 \\
\hline Minorista & 30.5 & 28.5 & 28.5 \\
\hline Acumulación Simple & 27.5 & 25.5 & 25.5 \\
\hline Acumulación Ampliada & 25.5 & 23.5 & 23.5 \\
\hline
\end{tabular}

Nota: * Subsegmento del Microcrédito creado a partir del 2019.

Fuente: Banco Central del Ecuador. Elaboración propia.

El sistema de amortización de estas entidades está dado por el método francés y alemán, destacando que en el país es común utilizar el método de amortización francés en vista de que las cuotas son mensuales e iguales en cada plazo de vencimiento de la operación. Las mensualidades que se cancelan a lo largo de la vida del préstamo están formadas por el costo financiero, en función del tiempo y la amortización del préstamo.

Para otorgar y acceder a los microcréditos, la Asamblea Nacional del Ecuador (2018) aprobó la "Ley para Fomento Productivo, Atracción, Inversiones, Generación de Empleo", de tal forma que dio a conocer que el servicio de referencias crediticias será prestado por la Superintendencia de Bancos, entidad que está facultada para supervisar y controlar el ejercicio de sus actividades.

\section{Los microcréditos y su incidencia en la pobreza}

Pobreza según la definición de la Academia Ecuatoriana de la Lengua, proviene del latín pauper, -êris; cualidad de pobre, característica que define al ser humano necesitado, que no tiene lo necesario para vivir. El Banco Mundial, con un concepto más técnico, define a la pobreza como la incapacidad para alcanzar un nivel de vida mínimo.

La Organización de las Naciones Unidas para la Educación, la Ciencia y la Cultura (Unesco), establece que son tres las perspectivas que deben considerarse al evaluar si un individuo está en situación de pobreza:

1. Si su ingreso está por debajo de una línea de pobreza. 
2. Si posee los servicios básicos necesarios.

3. Si tiene las suficientes capacidades básicas para funcionar en sociedad.

Haughton y Khandker (2009) conceptualizan a la pobreza como la privación de bienestar de manera pronunciada, es decir, la falta de acceso a capacidades básicas para funcionar en la sociedad y la carencia de un ingreso adecuado para enfrentar necesidades de educación, salud, seguridad, empoderamiento y derechos básicos.

Cada país, bajo sus apreciaciones y tomando en consideración la concepción mundial que tiene el término, encarga a cierto órgano gubernamental para que midan su nivel de pobreza nacional; en México está el Consejo Nacional de Evaluación de la Política de Desarrollo Social (Coneval), en Colombia el Departamento Administrativo Nacional de Estadística (DANE), mientras que en Ecuador esta competencia la tiene el Instituto Nacional de Estadísticas y Censos (INEC). Esta institución periódicamente pone de manifiesto a la colectividad los resultados de sus estudios. En la Figura 1 se observa el nivel de pobreza por ingresos sectorizados y también global. Esta información muestra que el nivel de pobreza ha crecido durante el año 2019, situación que se debe principalmente a la pérdida de empleo o la dificultad de los integrantes de la familia para conseguir empleo por falta de estudios, experiencia y, en muchos casos, por la crisis económica propia del país.

Figura 1: Índice de pobreza

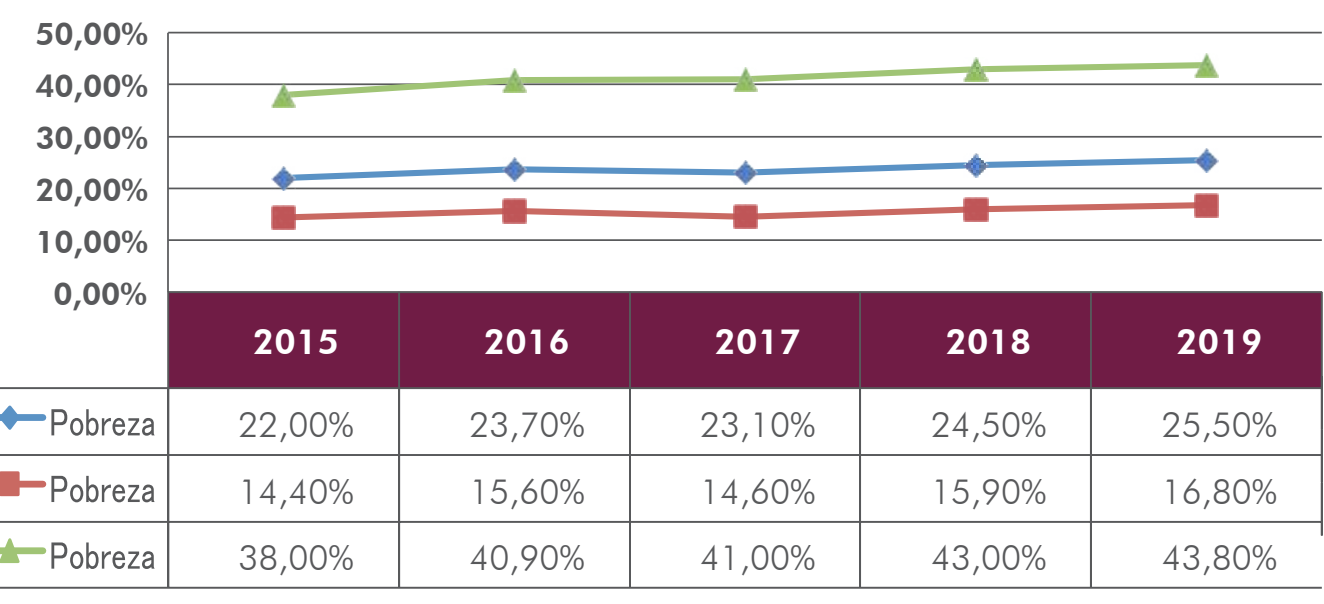

Nota: Obtenido de Encuesta Nacional de empleo, desempleo y subempleo ENEMDU, 2019 
La pobreza se encuentra inmersa en todos los países del mundo, solo que en unos está más presente que en otros, para contrarrestar ese problema existen algunas facilidades que los bancos han desarrollado siguiendo un modelo ambiguo, pero que ha resultado muy eficaz. Ese patrón consiste en otorgar microcréditos a pequeños comerciantes o personas que viven del emprendimiento, por eso las instituciones financieras se apalancan en ellos para emplear los diferentes préstamos (Cevallos Bravo, 2016).

Para Rosenberg (2010)

La pobreza económica no es solo un problema de ingresos bajos, también es un problema de ingresos irregulares e inciertos. Para poder llevar la comida a la mesa todos los días y para satisfacer otras necesidades de consumo básicas, los hogares pobres tienen que ahorrar y pedir prestado constantemente (p. 2).

Las personas pobres usan los créditos y ahorros no solo para el consumo, sino también para problemas de salud, para hacer frente a las oportunidades -generalmente de negocios-, y afrontar gastos como la educación. Para Gutiérrez (2009), las personas necesitan dinero con cierta frecuencia para: "Asuntos cíclicos de la vida (nacimientos, domicilio, educación, alimentación), emergencias personales (enfermedades, guerras) y oportunidades (creación de negocios, compra de activos)"

Amartya Sen (2000, cit. por Rentería Guerrero, 2005) "ha mencionado insistentemente al microcrédito como un elemento esencial para la generación de autoempleo en las familias de los países más pobres del mundo". Los hogares pobres valoran los microcréditos porque financian inversiones en microempresas que ayudan a disminuir la pobreza de sus dueños y les permite hacer frente a sus condiciones de vulnerabilidad. Es así que las instituciones bancarias que ofertan dentro de su cartera microcréditos se han convertido en una herramienta para combatir la pobreza, además del impulso que el Estado está dando. Es importante considerar que las instituciones bancarias no solo proveen dinero a través del microcrédito, sino que promueven programas de ahorro, además de actividades relacionadas con la salud, planificación familiar y manejo de bienes. Lo que buscan es darles las herramientas necesarias a las personas de bajos recursos para mejorar su autoestima frente a la sociedad e integrarse a ella generando producción y consumo.

Según Castillo (2008) "los programas de microcrédito son focalizados y su población objetiva suele estar conformada por gente pobre que no tiene acceso a los préstamos institucionales de la banca comercial o de otras instituciones públicas" (p. 96).

Las personas pobres tienen la capacidad de emprender y convertirse potencialmente en generadores de ingresos. Se los conoce como pobres emprendedores debido a que cuentan con habilidades personales para los negocios, diferenciándose de aquellos, que no tienen capacidades para ejercer actividades económicas o que se encuentran en estado de indigencia.

El identificar a la población objetiva es importante para la creación de programas crediticios. Los jefes de familia constituyen un grupo objetivo común en las instituciones financieras porque han demostrado el deseo de superación para mejorar las condiciones de vida de los suyos. Por otra parte, los jefes de hogar tienen acceso a los créditos porque generalmente los activos que pueden servir como garantías están registrados a su nombre. El microcrédito no solo mejora la situación económica del cabeza del hogar, sino de toda la familia y de la sociedad; además, lo empodera para tomar decisiones.

Los préstamos funcionan entregando por un periodo corto un monto pequeño de acuerdo a la capacidad de pago del prestatario; al 
cancelar el primer préstamo otorgado puede acceder a otro con un monto mayor. Si el prestatario cancela los montos otorgados de acuerdo al tiempo establecido puede acceder a montos cada vez mayores. Esta política es aplicada debido a que la gente pobre no tiene suficientes activos que sirvan de garantía, lo cual representa un obstáculo para acceder a créditos de instituciones bancarias tradicionales. Los microcréditos son valiosos para las familias que están dispuestas a pagar tasas de interés elevadas por los préstamos, porque consideran que mejoran su nivel de vida (Rosenberg, 2010).

Al respecto, Martinez Solarte (2013) indica que:

El microcrédito es un ingreso efímero, no constante, que implica no solo el reintegro del dinero objeto de préstamo, sino además de ello, por la naturaleza del crédito que resulta riesgoso y no tiene garantías reales; se ha instituido como estrategia financiera la imposición de altas tasas de interés (p. 21).

Para Asqui \& Soria, (2020) "el microcrédito es una base de sustento en las familias que aportan a la economía. Las microempresas en este contexto constituyen fuentes de generación de empleo" ( $p$. 184). Los microcréditos promueven el desarrollo de microempresas y de esta forma procuran contribuir a la generación de mayores ingresos, mayores fuentes de empleo y volver más dinámico el sector informal; contribuyendo de esta forma al desarrollo económico de los países (González-Vega, Prado y Miller, 2002). El crecimiento económico es necesario para contribuir a mitigar la pobreza, si las familias generan ingresos al emprender negocios con el apoyo de las instituciones bancarias, obtendrán a nivel individual acceso a la educación, salud y oportunidades laborales; en el ámbito familiar podrán acceder a la distribución de los activos y mayor bienestar (Espinoza, 2015).

\section{Ventajas y desventajas del microcrédito}

Entre las ventajas de entregar microcréditos se encuentran:

- Acceso a recursos económicos para microempresarios

- Seguridad de disponer de recursos con instituciones fiables

- Posesión de derechos con relación a la institución financiera

- Costo financiero más bajo que acceder a préstamos informales

Las desventajas asociadas a la emisión de microcréditos son:

- El dinero no es utilizado en el negocio, sino para cubrir deudas personales

- El monto del préstamo no alcanza para financiar la idea de negocio del prestamista

- Períodos de pago cortos que dificulta formar un capital sólido

- No contar con garantías aceptables para la institución financiera

Con este análisis se reconoce que los microcréditos también poseen desventajas que afectan directa $\circ$ indirectamente al microempresario o jefe de hogar que solicita un préstamo. Por tal motivo, la persona que se haga acreedora de este préstamo debe invertir y distribuir correctamente el capital recibido por parte de la entidad bancaria. Los individuos necesitan tener un plan estratégico para que las inversiones a realizar en los diferentes emprendimientos o negocios resulten productivas, pues de esa forma podrán obtener beneficios económicos y parte de la liquidez que adquieran será para cubrir la deuda generada con el respectivo banco prestamista.

Finalmente, las personas deberán analizar cada escenario antes de colocar el negocio en marcha, caso contrario, su primer historial crediticio quedará manchado por no haber planificado correctamente las actividades que pensaban realizar con el dinero del préstamo o porque se endeudaron más de lo debido para conseguir insumos, que posiblemente no necesitaba en primera instancia. 


\section{MATERIALES Y MÉTODOS}

La metodología del artículo consiste en una investigación documental, porque se analizaron los montos de los créditos desde el 2015 al 2019 considerando información de fácil acceso al público a través de la página web de la Superintendencia de Bancos.

La investigación es de carácter exploratoria, descriptiva y aplica una investigación de campo porque se hicieron observaciones in-situ a través de encuestas para examinar a usuarios de microcréditos del sistema financiero ecuatoriano. Para propósitos del análisis se ha considerado a los beneficiarios de microcrédito de la ciudad de Milagro perteneciente a la provincia del Guayas. La población objeto de análisis para el año 2019 estuvo conformada por 361610 operaciones de crédito según el director Julio José Prado, Presidente Ejecutivo de Asobanca. Debido al tamaño de la población, Morales (2012) afirma que "cuando la población es muy grande (más de 300000 sujetos) se puede utilizar la fórmula para poblaciones infinitas". Con base en esta información se aplicó un muestreo no probabilístico, tomando un margen de error del $10 \%$ y un nivel de confianza del $90 \%$, dio como resultado una muestra de 68 usuarios de microcréditos.

$$
\begin{gathered}
n=\frac{Z^{2} p q}{e^{2}} \\
n=\frac{1.65^{2}(0.50)(0.50)}{0.10^{2}} \\
n=68
\end{gathered}
$$

\section{RESULTADOS Y DISCUSIÓN}

Es necesario precisar que esta encuesta está dirigida a conocer si los microcréditos incentivan la reducción de la pobreza y contribuyen a la mejora del ingreso familiar. Luego de aplicar la encuesta se obtuvieron los siguientes resultados:

Tabla 2: Destino del crédito

\begin{tabular}{lll}
\hline ALTERNATIVAS & RESULTADOS & PORCENTAJES \\
\hline Emprender un negocio & 32 & $47 \%$ \\
Consumo & 1 & $1 \%$ \\
Capital de trabajo & 15 & $22 \%$ \\
Actividades de comercio y & 20 & $29 \%$ \\
producción & 68 & $100 \%$ \\
\hline TOTALES & 68
\end{tabular}

Nota: Datos obtenidos mediante encuesta

Cuando se preguntó a los usuarios del microcrédito sobre el destino del dinero solicitado, el $47 \%$ respondió que era para emprender un negocio. Dada la situación económica que viven, consideran que es una forma de generar ingresos para sus familias. Recalcan que actualmente existen dificultades para acceder a empleos estables, y las pocas ofertas de trabajo que hay solicitan varias cualificaciones que, en la mayoría de los casos, no poseen. Por lo tanto, la opción de abrir un negocio propio se torna la mejor alternativa para sustentar a sus familias.

El 29 \% afirma que los préstamos recibidos por las instituciones bancarias los utilizaron en actividades de comercio y producción, debido a que actualmente cuentan con un emprendimiento y buscan a través del préstamo una forma de mantener sus negocios o adquirir los insumos necesarios para llevar a cabo sus actividades. El $22 \%$ menciona que solicitaron un microcrédito para capital de trabajo 
porque buscan invertir dinero para cubrir los gastos propios de sus actividades. Por último, solo el 1 \% afirmó que el crédito solicitado lo utilizó en actividades de consumo, colocando a este prestamista en una situación difícil si no tiene la capacidad, a través de su negocio, de cubrir los valores adeudados. Para evitar esta situación, los asesores de crédito deben doblar esfuerzos por asegurarse que los microcréditos sean destinados a actividades económicas y así evitar por un lado, el riesgo de la entidad bancaria de no recibir el dinero prestado y, por otro lado, el riesgo de los prestamistas de sobreendeudarse y empeorar su situación económica. Con estos antecedentes se destaca que el crédito bien administrado contribuye a la generación de ingresos, pero si es mal utilizado, puede originar un mayor nivel de pobreza al prestatario, situación que confirma la tabla 3 .

Tabla 3: Resultados por acceder al crédito

\begin{tabular}{lll}
\hline ALTERNATIVAS & RESULTADOS & PORCENTAJES \\
Mejoras en la calidad de vida & 20 & $29 \%$ \\
Mayores ingresos & 35 & $51 \%$ \\
Adquisición de bienes & 13 & $19 \%$ \\
personales & 68 & $100 \%$ \\
\hline TOTALES & 68
\end{tabular}

Nota: Datos obtenidos mediante encuesta

El $51 \%$ de los encuestados afirman que luego de obtener su microcrédito han aumentado sus ingresos porque el dinero solicitado lo invirtieron en su negocio, generando ganancias que han permitido cancelar el crédito recibido dentro de los tiempos establecidos. Según la Tabla 3, el $29 \%$ de los beneficiarios de los microcréditos aseguran que su calidad de vida ha mejorado, porque sus negocios están generando dinero para solventar sus necesidades básicas. El $19 \%$ menciona que los microcréditos, luego de ser utilizados en los negocios, les han permitido adquirir bienes personales. Cabe señalar que los usuarios de microcréditos bancarios ven en los préstamos una opción para mejorar principalmente sus ingresos y con ello mejorar su calidad de vida y la de su familia, generando flujo de dinero dentro del país.

Tabla 4: Actividad del prestatario

\begin{tabular}{lll}
\hline ALTERNATIVAS & RESULTADOS & PORCENTAJES \\
\hline Comercio & 37 & $54 \%$ \\
Servicios & 20 & $29 \%$ \\
Manufactura & 8 & $12 \%$ \\
Agricultura, ganadería y pesca & 3 & $4 \%$ \\
\hline TOTALES & 68 & $100 \%$
\end{tabular}

Nota: Datos obtenidos mediante encuesta

La Tabla 4 explica las actividades que realizan los prestatarios. El $54 \%$ de los encuestados se dedica a actividades comerciales, el $29 \%$ se dedica a actividades de servicio, el $12 \%$ realiza actividades de manufactura, entre las que tenemos la elaboración de productos químicos, fábrica de muebles y calzado, entre otras, y el $4 \%$ de los usuarios de microcréditos se dedican a actividades relacionadas con la agricultura. Estos resultados muestran que existen varios negocios que son el sustento de las familias y que requieren de dinero para mantenerse o expandirse. Los cambios constantes en los precios de los productos dentro del país los llevan a solicitar créditos, siendo la mejor opción los microcréditos porque poseen capitales limitados.

Como parte del análisis se revisó la evolución del microcrédito desde el 2015 hasta el 2019. De acuerdo a la Tabla 5, se puede observar que el microcrédito ha pasado de 1900 millones de dólares en el 2015 a más de 2700 millones de dólares en el 2019, incrementando 
paulatinamente la cartera de crédito por el interés de los empresarios o emprendedores de acceder a recursos económicos. Se demuestra que las microfinanzas son consideradas por los prestatarios como una herramienta invaluable para disminuir los índices de pobreza en países en vías de desarrollo. Facilitar recursos a los deficitarios del mismo para crear oportunidades de nuevos negocios permite que el círculo vicioso de la pobreza se desvanezca.

Tabla 5: Evolución de la cartera en millones de dólares

\begin{tabular}{|llllll|}
\hline $\begin{array}{l}\text { Cartera de } \\
\text { créditos }\end{array}$ & $\mathbf{2 0 1 5}$ & $\mathbf{2 0 1 6}$ & $\mathbf{2 0 1 7}$ & $\mathbf{2 0 1 8}$ & $\mathbf{2 0 1 9}$ \\
\hline Comercial & 20,781 & 19,539 & 19,640 & 23,052 & 22,968 \\
\hline Consumo & 2,187 & 2,210 & 2,455 & 2,790 & 3,501 \\
\hline Productivo & 311 & 880 & 1,541 & 1,610 & 2,053 \\
\hline Microcrédito & 1,927 & 2,055 & 2,328 & 2,576 & 2,777 \\
\hline
\end{tabular}

Nota: Obtenido de Superintendencia de Bancos del Ecuador. Elaboración propia

Según El Telégrafo (2011) "La cartera micro financiera del país supera los USD 2000 millones en créditos entregados a un millón de microempresarios, lo que da beneficios a seis millones de personas, directa e indirectamente". En lo que respecta al 2019, según la Superintendencia de Bancos (2019), los microcréditos en Ecuador ocupan el tercer puesto por montos otorgados en el 2019. Esto se debe a los incentivos que se dan en la actualidad para acceder a préstamos bancarios. Sin embargo, según Carvajal-Salgado, Michilena Chila, \& Acuña Corredor (2018) "la financiación bancaria todavía presenta dificultades de acceso, producto de la asimetría de la información de las microempresas y que no cuentan con mayores garantías que les permitan asumir los préstamos".

Acorde a lo mencionado, se puede decir que los pequeños préstamos de dinero están dando resultado. Por ende, el crecimiento económico se da tanto a nivel de negocios como de forma personal, conllevando a que los ciudadanos hayan renovado sus situaciones financieras y formas de vida; ya que las personas o familias destinan los recursos de liquidez para invertir en lo que realmente necesiten y poco a poco ir perfeccionando la infraestructura de su actividad. Es importante resaltar que la pobreza en el país ha incrementado por la reducción de puestos de trabajo y limitadas oportunidades laborales, siendo los micro emprendimientos la oportunidad de las familias para generar ingresos. Los microcréditos se orientan a financiar a personas pobres que desean emprender o a los pequeños negocios o microempresas ya existentes. De esta manera, demuestra ser una herramienta útil para combatir la pobreza en distintos lugares del país y consecuentemente están siendo ofertados en diferentes modalidades.

Al analizar la evolución de la cartera de microcrédito (Tabla 6) se observa que los bancos se concentran más en el subsegmento de acumulación simple, puesto que son los más aceptados por personas no incluidas en los otros tipos de crédito. Esto representa en promedio más de USD 1000 millones equivalente al $51 \%$ de los montos entregados durante los años 2015 al 2019. Además, esto se debe principalmente a la situación económica del país, que genera que los dueños de negocios inviertan en productos innovadores para mantenerse en el mercado, requiriendo para ello mayores sumas de dinero. 
Microcréditos ecuatorianos: incentivo a la reducción de la pobreza y mejora del ingreso familiar Ana Carvajal Salgado, Leonela Espinoza Párraga • VÍNCULOS-ESPE (2020) VOL.5, No.3: 51 - 65

Tabla 6: Evolución de la cartera de microcrédito en millones de dólares 2015-2019

\begin{tabular}{|c|c|c|c|c|c|c|c|}
\hline $\begin{array}{l}\text { Tipo de } \\
\text { microcrédito }\end{array}$ & 2015 & 2016 & 2017 & 2018 & 2019 & Promedio & $\%$ \\
\hline $\begin{array}{l}\text { Acumulación } \\
\text { ampliada }\end{array}$ & 342,1 & 576,6 & 689,5 & $1,466,9$ & $1,548,6$ & 924,8 & $37 \%$ \\
\hline $\begin{array}{l}\text { Acumulación } \\
\text { simple }\end{array}$ & $1,551,0$ & $1,369,8$ & $1,523,1$ & $1,013,0$ & 938,4 & $1,279,1$ & $51 \%$ \\
\hline Minorista & 34,2 & 108,7 & 110,9 & 96,0 & 61,7 & 82,3 & $3 \%$ \\
\hline $\begin{array}{l}\text { Microcrédito } \\
\text { agricultura y } \\
\text { ganadería }\end{array}$ & - & - & - & - & 228,9 & 228,9 & $9 \%$ \\
\hline
\end{tabular}

Nota: Obtenido de Superintendencia de Bancos del Ecuador. Elaboración propia

En lo que respecta al microcrédito de acumulación ampliada, este representa en promedio el $37 \%$ de la cartera de microcréditos, dado que sus montos de préstamo son mayores a los USD 10000 y con ello representa mayores riesgos a las microempresas. En contraste, los microcréditos minoristas ocupan el $3 \%$ de la cartera de microcrédito, principalmente porque los montos son inferiores a los USD 3 000, capital que en muchos casos no permite realizar la inversión deseada por el emprendedor o dueño del negocio. Los subsegmentos de agricultura y ganadería recientemente incorporados al segmento de microcréditos (a partir del 2019) representan el $9 \%$ en promedio de la cartera de microcrédito, principalmente porque no todos los agricultores y ganaderos conocen de su implementación y beneficios, siendo necesario mayor promoción para este tipo de crédito. Cuando los clientes que antes no podían acceder a créditos se les habilita la posibilidad de obtener uno, acuden a las instituciones financieras y además sirven como medio de publicidad al llevar la noticia a otros posibles clientes.

\section{CONCLUSIONES}

Las Instituciones financieras en el Ecuador han cumplido uno de los propósitos del Estado, colocando millones de dólares en el mercado para que los microempresarios lo tomen como alternativa en su búsqueda de mejoras; logrando desde la percepción de los emprendedores ecuatorianos, mejorar la calidad de vida de sus familias.

A partir del instrumento aplicado fue posible obtener información sobre las razones que tuvieron los prestatarios para acceder a un crédito, resaltando mayoritariamente el deseo de emprender su propio negocio. Los pobres emprendedores consideran a los micronegocios como mecanismo para sustentarse y satisfacer sus necesidades como salud, educación y alimentación.

Con relación al destino de los créditos, se encontró que el $51 \%$ de los encuestados consideran que los microcréditos contribuyen 
a incrementar sus ingresos, por esta razón los microcréditos presentaron un incremento en sus montos de colocación del 2015 al 2019. Los microempresarios que obtienen préstamos tienen mayor ímpetu para desarrollar sus actividades económicas y manifiestan que han mejorado su nivel de vida gracias a las microfinanzas. Los clientes de los servicios financieros valoran a los microcréditos al considerarlos que son herramientas de superación, porque contribuyen a disminuir sus niveles de pobreza.

Los microempresarios que mayoritariamente solicitan créditos son los dedicados a actividades comerciales. Establecen pequeños negocios donde comercializan productos perecederos y no perecederos. Con estos trabajos productivos los jefes de hogar obtienen ingresos para satisfacer sus necesidades y mejorar sus condiciones de vida.

En este documento se pone de manifiesto la relevancia de los microcréditos en Ecuador como herramienta de empoderamiento que contribuye a reducir la pobreza familiar. Es importante resaltar que los microcréditos no ayudan a erradicar la pobreza, pero sí generan beneficios para elevar los ingresos de los pobres emprendedores y ayudan a lidiar con las circunstancias que estén atravesando. Con lo observado, es imposible afirmar que los préstamos reduzcan la pobreza en un año de microcrédito pero, si las instituciones bancarias otorgan microcréditos de forma permanente, pueden seguir prestando dinero año tras año, posibilitando expandir este servicio a un mayor número de clientes. Los servicios que ofrecen las instituciones bancarias que otorgan microcréditos abren a los pobres emprendedores la oportunidad de mejorar las condiciones precarias en las que viven e incrementar sus ingresos mediante el desarrollo de sus habilidades.

Desde la perspectiva de las familias se concluye que el microcrédito es un mecanismo para aliviar la pobreza, siempre y cuando el crédito sea bien administrado, porque incrementa el ingreso y el consumo de las familias pobres, aumenta sus activos, disminuye su exclusión de la sociedad, mejora la salud, aumenta el nivel de escolaridad, le otorga poder para influir en el mejoramiento familiar y disminuye el problema económico.

Se considera necesario establecer nuevas rutas de microcréditos, especialmente al sector rural ecuatoriano porque es ahí donde se concentra el mayor nivel de pobreza. Es recomendable que el Estado tenga una mejor posición en la oferta de financiamiento para emprendedores mediante Instituciones Gubernamentales que flexibilicen las políticas de crédito permitiendo mayor acceso en la zona rural a este producto financiero, ya que en su mayoría este sector se compone de pequeños agricultores.

\section{REFERENCIAS}

Aguilar Pinto, E. D. C., Tuñón Pablos, E., \& Morales Barragán, F. (2017). Microcrédito y pobreza. La experiencia del programa Microempresas Sociales de Banmujer en Chiapas. Economía Sociedad y Territorio, XVII(1), 809-835. https://doi. org/10.22136/est2017885

Asamblea Nacional del Ecuador. (2018). Ley para fomento productivo, atracción, inversiones, generación de empleo. Dirección Nacional Jurídica. https://www.gob.ec/sites/default/ files/regulations/2018-09/Documento Ley-Org\%C3\%A1 nicaFomento-Productivo-Atracci\%C3\%B3n-Inversiones.pdf

Asqui, R., \& Soria, N. (2020). Factores de incidencia en la obtención de crédito en la microempresa. Yura: Relaciones Internacionales, 53(21), 165-188. https://doi.org/10.1017/ CBO9781107415324.004

Banco Central del Ecuador. (2012). Libro I Política monetaria-creditica. Ecuador. https://www.bce.fin.ec/documents/pdf/general/Librol. $\mathrm{pdf}$ 
Carballo, N., \& Carnero, F. (2016). El Microcrédito. Tesis de grado. https://www.bce.fin.ec/documents/pdf/general/Librol.pdf

Carvajal-Salgado, A. L., Michilena Chila, C. A., \& Acuña Corredor, G. A. (2018). Decisiones de financiamiento en empresas del sector de alojamiento y servicios de comida: Trade Off vs. Pecking Order. Killkana Social, 2(4), 21-32. https://doi.org/10.26871/ killkana_social.v2i4.96

Castillo, A. D. M. (2008). El microcrédito como instrumento para el alivio de la pobreza: Ventajas y limitaciones. Cuadernos de Desarrollo Rural, 5(61), 93-110.

Cevallos Bravo, M. (2016). Impacto de los microcréditos en la generación de créditos en el sector sur de la ciudad de Quito. Revista Publicando, 3(9), 589-610.

El Telégrafo. (201 1). Los microcréditos mejoran la calidad de vida de millones de ecuatorianos. Recuperado en octubre 14, 2019, de https://www. eltelegrafo.com.ec/noticias/sociedad/4/los-microcreditos-mejoranla-calidad-de-vida-de-millones-de-ecuatorianos

Espinoza, M. C. (2015). El Microcredito como motor de Desarrollo de la Microempresa en Guayaquil. Universidad de Guayaquil. http://repositorio.ug.edu.ec/bitstream/redug/8501/1/Tesis Maria Cristina Espinoza Lozano.pdf

Gutiérrez, J. (2009). Microfinanzas y desarrollo: Situación actual, debates y perspectivas. Cuadernos de Trabajo Hegoa, 0(49).

Gutiérrez Nieto, B. (2003). Microcrédito y desarrollo local. Acciones e Investigaciones Sociales, 18(18), 115-128. https://doi. org/10.26754/ojs_ais/ais.200318265

Haughton, J., \& Khandker, S. (2009). Handbook Poverty + Inequality. El Banco Mundial.
INEC. (2020). Encuesta de empleo, Desempleo y Subempleo. Recuperado en Junio 15, 2020, de https://www.ecuadorencifras. gob.ec/empleo-desempleo-y-subempleo/

Inglada, M. E., Sastre, J. M., \& de Miguel Bilbao, M. C. (2015). Importancia de los microcréditos como instrumento de financiación en el desarrollo social. Revista Guillermo de Ockham, 13(2), 89. https://doi.org/10.21500/22563202.2264

Junta de Política Monetaria y Financiera. (2019). Resolución No. 496-2019-F. https://contenido.bce.fin.ec/docs.php?path=/ documentos/Estadisticas/SectorMonFin/TasasInteres/Indice.htm

Junta de Regulación Monetaria y Financiera. (2015). Resolución No. 043-2015-F. Journal of Chemical Information and Modeling. https://doi.org/10.1017/CBO9781107415324.004

Junta de Regulación Monetaria y Financiera. (2018). RESOLUCIÓN No. 437-2018-F. Ecuador. https://contenido.bce.fin.ec/ documentos/Estadisticas/SectorMonFin/Tasas/nteres/ Resolucion-437-2018-F.pdf

Martinez Solarte, P. (2013). Efectos del microcrédito en la calidad de vida de los microempresarios. (Ensayo de especialización). Universidad Militar Nueva Granada. https:// repository.unimilitar. edu.co/bitstream / handle / 10654 / 11568/ EFECTOS DEL MICROCREDITO EN LA CALIDAD DE VIDA DE LOS MICROEMPRESARIOS.pdf; isessionid $=$ C91E76E8899AC8441F5E01EAC601BCC 1 ? sequence $=1$

Mazón, E. O. (2018). Formalización de las Microfinanzas y su Impacto en el Desarrollo del Sistema Financiero Ecuatoriano. Superintendencia de Bancos, (2), 32. http://estadisticas. superbancos.gob.ec/portalestadistico/portalestudios/wpcontent/uploads/sites/4/downloads/2018/09/formalizacion_ microfinanzas 2018.pdf 
Montalvo Corzo, R. F., Vázquez Parra, J. C., \& Amézquita Zamora, J. A. (2018). Desigualdad, microcréditos y desarrollo sostenible: un estudio en la Zona Metropolitana de Guadalajara. CIENCIA Ergo Sum, 25(1). https://doi.org/10.30878/ces.v25n1a2

Morales, P. V. (2012). Muestras probabilísticas o aleatorias. Estadística Aplicada a Las Ciencias Sociales, 2-3. http://web.upcomillas. es/personal/peter/investigacion/TamañoMuestra.pdf

Orozco, M. (2015). 10 nuevos tipos de crédito están en vigencia en Ecuador. El Comercio. Recuperado en octubre 14, 2019 de https://www.elcomercio.com/actualidad/nuevos-tipos-creditovigentes-ecuador.html

Rentería Guerrero, L. (2005). El microfinanciamiento: una alternativa en el combate a la pobreza extrema en Sonora. Estudios Sociales: Revista de Investigación Científica, 13(25), 93-139.

Rosenberg, R. (2010). ¿̇El microcrédito ayuda realmente a los pobres? Enfoques, 59(2005), pp.105-137. https://doi. org/10.1080/17532520903564829

Salgado, G., \& Andrade, R. (2011). Potencial de las finanzas éticas en el desarrollo del microcrédito en el Ecuador. (Tesis de grado). Pontificia Universidad Católica del Ecuador. http:// repositorio.puce.edu.ec/bitstream/handle/22000/4591/TESIS. $\mathrm{pdf}$ ? sequence $=3$ \&isAllowed $=\mathrm{y}$

Superintendencia de Bancos. (2019). Volumen de Crédito - Portal de estudios. Recuperado en octubre 18,2019, de http://estadisticas. superbancos.gob.ec/portalestadistico/portalestudios/?page_ $\mathrm{id}=327$

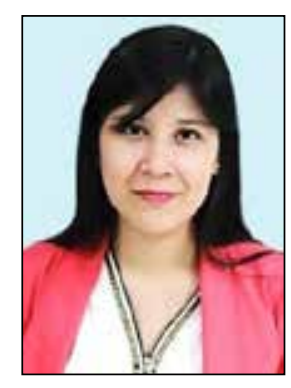

ING. ANA CARVAJAL SALGADO, MGS.

- Magister en Contabilidad y Finanzas de la Universidad Espíritu Santo

- Ingeniera en Contaduría Pública y Auditoría - CPA de la Universidad Estatal de Milagro.

- Contador bachiller

\section{Experiencia profesional}

- Docente de la Universidad Estatal de Milagro

- Docente del pre-universitario de la Universidad Estatal de Milagro

- Analista contable en CNEL EP. Santa Elena

- Asistente contable en Devies Corp.

- Asistente administrativa - contable en Arte Milagro

- Ejecutiva de atención al cliente en Banco D-Miro

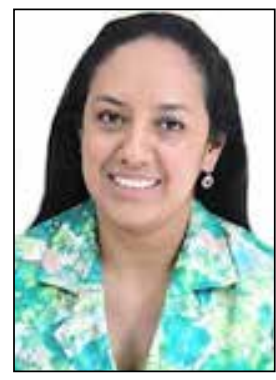

ING. LEONELA ESPINOZA PÁRRAGA, MGS.

- Magister en Contabilidad y Auditoría por la Universidad Laica Vicente Rocafuerte.

- Especialista en Gestión Pública del Instituto de Altos Estudios Nacionales IAEN

- Ingeniera Comercial de la Universidad Estatal de Milagro

Contador Bachiller

Experiencia profesional

- Docente y expositor en varias universidades y Colegios de Contadores.

- Contadora de la Junta de Riego y Drenaje MilagroMariscal Sucre.

- Asesora Financiera, Administrativa y Contable en Comadvisory. 